\title{
Who Experience Out-of-Pocket Expenditures for Modern Contraceptive Use in Indonesian Universal Health Coverage System?
}

\author{
Dedik Sulistiawan ${ }^{1}$, Lutfan Lazuardi ${ }^{2}$, Relmbuss Biljers Fanda ${ }^{3}$, Muhammad Asrullah ${ }^{3}$, Ratu Matahari ${ }^{1}$, \\ Riza Fatma Arifa ${ }^{4}$ \\ ${ }^{1}$ Lecturer, Department of Public Health, Faculty of Public Health Universitas Ahmad Dahlan Yogyakarta \\ Indonesia, ${ }^{2}$ Lecturer, Department of Health Policy and Management, Faculty of Medicine Public Health and \\ Nursing, Universitas Gadjah Mada, Yogyakarta Indonesia, ${ }^{3}$ Researcher, Center for Health Policy and Management \\ Faculty of Medicine Public Health and Nursing, Universitas Gadjah Mada, Yogyakarta Indonesia, \\ ${ }^{4}$ Researcher, National Population and Family Planning Board, Special Region of Yogyakarta, Indonesia
}

\begin{abstract}
Integration of family planning programs into the universal health coverage system is expected to improve access toreproductive health services. All people should have access to sufficient and qualified family planning services they need without financial hardship. This study aimed to examine out-of-pocket expenditures of contraceptive services and the associated factors among fertile age couples that influence their access to modern contraceptive services. It was quantitative research with a cross-sectional design. Data obtained from the Health and Demographic Surveillance System 2016 of Sleman Regency, Indonesia, were analyzed using multiple logistic regression to determine factors associated with out-of-pocket expenditures for contraceptive services. This study revealed that more than $70 \%$ of people should pay for contraceptive services even though they had registered as health insurance members. Public non-subsidized and private health insurance members were more likely to experience OOP expenditures than public-subsidized participants (AOR=3.12; $95 \% \mathrm{CI}=2.25-4.30$ and $\mathrm{AOR}=3.47 ; 95 \% \mathrm{CI}=1.60-7.52$, respectively). Short-term contraception users were more likely to experience out-of-pocket expenditures thanlong-term users $(\mathrm{AOR}=6.38 ; 95 \% \mathrm{CI}=4.79$ 8.50). Nearly three-quarters of health insurance participants experience out-of-pocket expenditures for contraceptive services. Out-of-pocket expenditures of contraceptive services significantly associate with the type of health insurance owned and the types of contraceptive methods used.
\end{abstract}

Keywords: Family planning, out-of-pocket, universal health coverage

\section{Introduction}

One of the critical equity issues in health systems is financial barriers ${ }^{1,2}$. Out-of-pocket payments represent approximately half or more of the total health

\section{Corresponding Author:}

\section{Dedik Sulistiawan}

Lecturer, Department of Public Health, Faculty of Public Health Universitas Ahmad Dahlan Yogyakarta Indonesia, Jl. Prof. Soepomo, SH, Warungboto, Yogyakarta, Indonesia 55164

E-mail: dedik.sulistiawan@ikm.uad.ac.id

Phone: +6285736810190 expenditure in some countries like the Philippines, Pakistan, Laos, Bangladesh, and Vietnam ${ }^{3}$. In Indonesia, health spending as the extent of gross domestic product (GDP) remains under average among the low-tomiddle-income countries ${ }^{4}$. The government of Indonesia presented the National Health Insurance (NHI) in 2014 for reacting to the high of OOP expenditure and its effect on access to health services by the poor ${ }^{5}$. However, the allocation of NHI to preventive and promotive services is relatively low. This challenge might encourage the high levels of OOP expenditure ${ }^{4}$, including family planning (FP) services ${ }^{6}$. 
Responding to these conditions, Indonesia ratifies the integration of the FP program into the $\mathrm{NHI}^{7}$. The FP program integration into the NHI scheme is expected to provide benefits for improving the access and quality of FP and reproductive health services ${ }^{8}$. Nevertheless, there are still people who receive FP services in the private sector by paying for contraceptives ${ }^{9}$. At the beginning of NHI implementation, the average OOP of health insurance participants is IDR 238,260.00 ${ }^{10}$. Based on data from the 2014 Indonesia Family Life Survey (IFLS), more than $5 \%$ of the Indonesian population experienced health expenditure of more than $40 \%$, which according to WHO standards, is categorized as catastrophic expenditure ${ }^{11}$.

Based on PMA2020, private facilities are the most predominant modern method source. The wealthiest segment paid the most out-of-pocket for FP services $^{6}$. Based on the 2017 IDHS data, more than thirty percent of women participating in FP received services from government sources; $21 \%$ have to pay for contraceptiveservices ${ }^{12}$. It seems that there are problems in access to sufficient and qualified contraceptive services, even though WHO declared that UHC should protect all people from financial hardship ${ }^{13,14}$. For these reasons, this study examines out-of-pocket OOP expenditures of contraceptive services and the associated factors among fertile age couples using the Sleman Health and Demographic Surveillance System (HDSS) 2016.

\section{Materials and Methods}

Study Design and Sample Selection: This study was quantitative research with a cross-sectional approach. Researchers conducted secondary data analysis to obtain information about access to FP services, especially out-of-pocket expenditure issues for health insurance participants in Sleman Regency using Sleman Health and Demographic Surveillance System (Sleman HDSS) 2016. Sleman HDSS is a populationbased survey that collects population transition, health status, and social transition periodically.

Sleman HDSS used a longitudinal design panel, which population was residents who live in Sleman Regency for six consecutive months. It involves a total of 5,147 selected households from 216 clusters in rural and urban districts. This study used Sleman HDSS Cycle
2 that was conducted in 2016. This study sample was 1,237 observations that met the inclusion criteria, i.e., aged 15 - 49 years, married or living with a partner, and health insurance members provided by the private sector and government.The Sleman HDSS obtained ethical permission from the Medical and Health Research Ethics Committee of Faculty of Medicine, Public Health, and Nursing, Universitas Gadjah Mada, with the number KE/FK/0434/EC.

Outcome Variable: OOPexpenditure of the FP service was the dependent variable in this study. In Sleman HDSS, OOP expenditures of FP services were assessed using how to pay the FP services. The response was classified into using health insurance facilities, paying with own money, distributing for free, and do not know. If the respondent answered with "pay with money" even though he/she was a health insurance member, we determined them as out-of-pocket expenditures.

Explanatory Variables: The essential sociodemographic characteristics of respondents that were considered included sex (male and female), age category (15-34 and 35-49), age of first marriage (under 21 and $21+$ ), education attainment (primary/ never attended, secondary-1, secondary-2, and university), parity (0-1 child, two children, and $3+$ children), and working status (housewife, formal sectors, and informal sectors). According to the Indonesian population control and FP program, age category was classified into younger and older age, education attainment was determined by formal years education, age of first marriage was defined according to the Indonesian maturation age of marriage program, and working status distinguished according to Indonesian Central Statistics Bureau. The main essential variables that were involved were the modern contraception method used that was dichotomized into LARC and short-acting methodusers, and the type of health insurance owned was classified into publicsubsidized, public-non-subsidized, and private insurance according to the Indonesian UHC system.

Data Analysis: The data obtained were analyzed using descriptive analysis to identify each research variable frequency distribution. It continued with crosstabulation to identify the difference ofOOP among several characteristics. We conducted a multiple logistic regressionto obtain the best model of factors related to 
OOP expenditure of FP services. The significance level was obtained from the magnitude of the p-value at the $5 \%$ significance level and the odds ratio using a $95 \%$ confidence interval. All analysis procedures were carried out using STATA version 14.2.

\section{Results and Discussions}

There were 5,147 selected households involved in this study, but only 1,237 observations met the inclusion criteria and were included in the final sample. Most of the respondents were primarily women and were categorized as old adults and already married. Respondents had various education levels; however,half of them completedsecondary school.Most respondents hadfewer than two children. The working status distribution showed that homemakers constituted the highest proportion of respondents.

While only $38.7 \%$ of respondents used the LARC and sterilization method, more than sixty percent of respondents reported usingshort-actingmethods. The data depicts that most of the respondents were public insurance members in terms of health insurance membership. It was only about $4.4 \%$ of respondents were private insurance participants. More than sixty percent of the respondents were public-subsidized beneficiaries. Even though all respondents were health insurance participants, both public and private, it is striking that more than $70 \%$ should pay for their contraceptive services. Most people experience OOP expenditure of FP services even though contraception was one of the benefit packages covered by health insurance in the Indonesian health insurance scheme (See Table 1).

Table1. Percentage Distribution of Respondents by Contraception Types, Health Insurance, and Payment for Contraceptive Services $(n=1,237)$

\begin{tabular}{|c|c|c|}
\hline Variable & $\mathbf{n}$ & $\mathbf{\%}$ \\
\hline Modern Method Used & & 38.7 \\
\hline LARC-Sterilization & 479 & 61.3 \\
\hline Short-acting Methods & 758 & 61.7 \\
\hline Type of Health Insurance Owned & & 33.9 \\
\hline Public-Subsidized & 763 & 4.4 \\
\hline Public-Non-Subsidized & 419 & \\
\hline Private Insurance & 55 & 26.6 \\
\hline Payment Category & & 73.4 \\
\hline Free & 908 & \\
\hline OOP Payment & 329 & \\
\hline
\end{tabular}


There were significant differences in the outof-pocket payment of contraceptives expenditures among different sex, age of first marriage, education attainment, parity, contraception methods, and type of insurance. Men tended to experience OOP higher than women. A similar pattern was observed for the age of first marriage, but with a minor difference. People who already got married under 21 years old were less likely to experience OOP. The data depicts that people with a higher education level tended to got OOP than lower educated ones. People who had more than two children were less likely to undergo OOP. It was unsurprisingly that short-acting methodusers tend to experience OOP than LARC users. This research also revealed that the public-subsidized insurance member was less likely to suffer from contraceptive servicesOOP.

Health insurance ownership status was one of the main factors that need to be considered in the OOP of FP services. OOP occurrence in FP acceptors who were participants of health insurance was a form of inefficiency in the health financing system. Besides, the modern method mix among married also hypothetically related to the OOP of FP services. Therefore, a multivariable analysis was conducted by considering other variables to get the adjusted odds ratio (OR) and the best model.

Model 1 shows the OR of OOP of FP services based on sociodemographic characteristics. Only parity was significantly associated with the OOP of FP services. The respondent who had three or more children was less likely to undergo OOP for FP services than with $0-1$ child (AOR $=0.47 ; 95 \% \mathrm{CI}=0.31-0.72)$. Nevertheless, in the full model, this predictor was no longer statistically significant. A similar pattern was observed for working status. In model 1 , there was no significant association between working status with OOP occurrence. However, in the full model, the formal sector was less likely to experience $\mathrm{OOP}$ than the housewife $(\mathrm{AOR}=0.59 ; 95 \%$ $\mathrm{CI}=0.37-0.94)($ See Table 2).

Table2. Structural Model and Odds Ratio of Factors Related to Out-of-Pocket Expenditures for Contraception Services in Sleman Regency, 2016

\begin{tabular}{|c|c|c|c|}
\hline \multirow{2}{*}{ Predictors } & Model 1 & Model 2 & Full Model \\
\hline & AOR $[95 \% \mathrm{CI}]$ & $\operatorname{AOR}[95 \% \mathrm{CI}]$ & $\operatorname{AOR}[95 \% \mathrm{CI}]$ \\
\hline \multicolumn{4}{|l|}{ Sex } \\
\hline Male & 1 & & 1 \\
\hline Female & $0.51 *[0.28-0.96]$ & & $1.01[0.52-1.98]$ \\
\hline \multicolumn{4}{|l|}{ Age Category } \\
\hline $15-34$ & 1 & & 1 \\
\hline $35-49$ & $1.20[0.87-1.65]$ & & $1.18[0.84-1.67]$ \\
\hline \multicolumn{4}{|l|}{ Age of First Marriage } \\
\hline Under 21 & 1 & & 1 \\
\hline $21+$ & $0.97[0.71-1.31]$ & & $0.99[0.71-1.38]$ \\
\hline \multicolumn{4}{|l|}{ Education Attainment } \\
\hline Primary/Never Attended & 1 & & 1 \\
\hline Secondary-1 & $1.10[0.72-1.69]$ & & $1.15[0.72-1.85]$ \\
\hline Secondary-2 & $1.46[0.98-2.17]$ & & $1.38[0.89-2.16]$ \\
\hline University & $1.66[0.98-2.80]$ & & $1.75[0.95-3.21]$ \\
\hline \multicolumn{4}{|l|}{ Parity } \\
\hline 0-1 Child & 1 & & 1 \\
\hline 2 Children & $0.76[0.52-1.10]$ & & $0.85[0.57-1.27]$ \\
\hline $3+$ Children & $0.47 * *[0.31-0.72]$ & & $0.66[0.41-1.05]$ \\
\hline
\end{tabular}


Cont.. Table2. Structural Model and Odds Ratio of Factors Related to Out-of-Pocket Expenditures for Contraception Services in Sleman Regency, 2016

\begin{tabular}{|c|c|c|c|}
\hline \multirow{2}{*}{ Predictors } & Model 1 & Model 2 & Full Model \\
\cline { 2 - 4 } & AOR [95\% CI] & AOR [95\% CI] & AOR [95\% CI] \\
\hline Working Status & & & 1 \\
\hline Housewife & 1 & & $0.59 *[0.37-0.94]$ \\
\hline Formal Sectors & $0.93[0.62-1.39]$ & & $0.90[0.65-1.25]$ \\
\hline Informal Sectors & $0.95[0.71-1.28]$ & & 1 \\
\hline Classification of Modern Methods & & & 1 \\
\hline LARC-Sterilization & & & $6.34^{* *}[4.66-8.62]$ \\
\hline Short-acting Methods & & $6.38^{* *}[4.79-8.50]$ & 1 \\
\hline Type of Insurance & & & $3.10^{* *}[2.12-4.53]$ \\
\hline Public-Subsidized & & $3.12^{* *}[2.25-4.30]$ & $3.42^{* *}[1.51-7.71]$ \\
\hline Public-Non-Subsidized & & $3.47^{* *}[1.60-7.52]$ & 1237 \\
\hline Private Insurance & 1237 & 1237 & 0.158 \\
\hline Observations & 0.029 & 0.150 & 1234.4 \\
\hline Pseudo R-squared & 1413.5 & 1225.3 & 1306.1 \\
\hline AIC & 1469.9 & 1245.8 & \\
\hline BIC & & & \\
\hline
\end{tabular}

AOR: Adjusted Odds Ratio; AIC: Akaike's Information Criterion; BIC: Bayesian Information Criterion

Exponentiated coefficients; 95\% confidence intervals in brackets; * $p<0.05, * * p<0.01$

The best model resulting from the multivariable analysis was the second model with the lower Akaike information criterion (AIC) and the Bayesian information criterion (BIC). Both in model 2 and the full model, types of modern method and health insurance owned were statistically associated with OOP of FP services. The short-acting methodsusers were more likely to experience OOP than LARC users $(\mathrm{AOR}=6.38 ; 95 \% \mathrm{CI}$ $=4.79-8.50)$. The public-non-subsidized insurance member and private insurance were more likely to suffer from OOP of contraceptive services than publicsubsidized members $(\mathrm{AOR}=3.12 ; 95 \% \mathrm{CI}=2.25-4.30$ and $\mathrm{AOR}=3.47 ; 95 \% \mathrm{CI}=1.60-7.52$, respectively)(See Table 2).

The contract system between the Indonesian health insurance implementing agency (BPJS Kesehatan) and all public health centers using a non-capitation scheme should reduce OOP $^{15,16}$, but the results of this study show different things. Findings in this study display a considerable percentage of respondents reporting that they paid for contraceptive services in the UHC scheme. The prior study stated that nearly two-thirds of Indonesia expenditure on the FP program comes from user expenses.PMA2020 data also showed that more than half of government FP providers charged FPservices in various levels of services ${ }^{17}$. It seems a sign that the Indonesia FP program strategy to provide free contraceptives through the NHIscheme is still erroneous.

There was a lack of comprehensive data to estimate OOP expenditure on reproductive health, including FP services. While FP services were intended to be free within the public health system, a study by ${ }^{18}$ indicated that only one-half of modern method users reported obtaining their free methods. A study in Burkina Faso also mentioned that reproductive health, including FPthrough the public health center, is paid ${ }^{19}$. PMA2020 examined that more than $70 \%$ of women paid for FP services, even though $60 \%$ of women receive their 
service from a public facility, where FP is supposed to be free. It suggested that OOP expenditure of FP services is ubiquitous ${ }^{20}$. This situation should be a challenge to advocate for the local government to increase the fund allocation for FP and scale-up insurance coverage based on the community level ${ }^{17,19}$.

It is interesting to note that OOP on FP services resulting from this study is significantly associated with health insurance ownership (public-subsidized compared to public non-subsidized and private insurances) and contraception types (LARC compared to short-acting methods). This finding has a similarity and contrast with the prior research about OOP determinants in several countries ${ }^{18,19,21-23}$. In the Indonesian UHC system, socioeconomic characteristics were determined by health insurance ownerships, wherein public-subsidized refers to lower-income groups, and non-subsidized and private insurance refer to wealthier segments. Even though some countries reported no significant differences by wealth quintile in the odds of obtaining free contraception ${ }^{18}$, the results of this study indicate that non-subsidized and private insurance were significantly associated with the out-of-pocket payment for contraceptive services.

The finding was consistent with studies conducted by Finer, Sonfield, \& Jones, which stated that out-ofpocket costs among privately insured women occurred for at least some methods of contraception-including oral contraceptives, the most popular reversible method in the United States ${ }^{23}$. This study also supports evidence from previous observations that the OOP of health expenditure, in general, has a significant association with socioeconomic status in Bangladesh. The OOP on health services is higher among the wealthiest people ${ }^{21}$. A similar pattern was also reported in India; the OOP was positively associated with the wealthiest quintile, suggesting that the burden was higher among those who could pay more ${ }^{22}$. This result indicates that NHI insurance coverage may be more critical for FP use among the poor than the rich as early as mentioned by Teplitskaya, Ross, and Arin ${ }^{6}$.

A desirable explanation for this might be that it was a higher use of short-acting methods in Indonesia among poor and rich segment ${ }^{6}$, as significantly proven by this study results. It was typical that using short-acting methods, particularly in LMICs, includes ease of access, privacy, freedom to discontinue use without involving a health provider, and lower cost ${ }^{24}$. In Indonesia, the average short-acting method OOP is approximately 1.47 $\mathrm{USD}^{6}$. These results corroborate the findings of previous work in several countries. In Kenya, users of implants and IUDs were more likely to report receiving their method for free than injectable users, who reported an average OOP payment of approximately $0.91 \mathrm{USD}^{18}$.

Previous studies in several LMICs have proven that the OOP of modern contraceptives mostly happened in private health services compared to government service $^{22}$. Indonesian Ministry of Health indicates that there are an estimated 163,541 midwives in Indonesia who lead private clinics. These practitioners are not adequately incentivized to practice in rural areas, preferring to practice in urban areas for nonfinancial and financial reasons ${ }^{25}$. These issues are particularly tricky, given that many people continue to access FP services through private sector midwives and pay out-of-pocket for the services.

It could also be because of the broad range of FP methods included within the NHIbenefits package, but both providers and clients strive to understand what is covered. Because of these confinements, FP is apportioned at the point of delivery, and out-of-pocket expenditure persists. Besides, not all FP methods are created equal. For example, the positioning of shortacting methods as "user-controlled commodities" will reduce the need for clients to interact with a health provider. Out-of-pocket payments are likely to continue to overwhelm this category of methods ${ }^{19}$.

Nonetheless, the findings do not explain how much users expense the OOP, including the actual cost associated with commodity, consultation, and transport to access FP services. We could also not examine the share of OOP expenditures for FP services from total household income to analyze FP services individual/ household burden. In the future study, it might be possible to use a different approach and datasets to answer the mentioned limitations.

\section{Conclusions}

Health insurance should improve the uptake of affordable FP services by reducing costs at the service point for users. Nevertheless, more than half of FP 
acceptors in the Sleman Regency should pay to get their FP services. Even though the poor segment is less likely to experience OOP expenditures than the wealthiest, OOP in FP services should be reduced to a minimum in all socioeconomic classes and health insurance membership segments. A more considerable effort is also needed to ensure that all modern methods are provided free in the UHC system.

Acknowledgment: The authors would like to acknowledge the Health and Demography Surveillance System (HDSS) Sleman team, Faculty of Medicine, Public Health, and Nursing, Universitas Gadjah Mada for the dataset used in this paper.

Conflict of Interest: The author declared that all authors had approved the manuscript, and there were no conflicts of interest associated with the material presented in this paper.

Source of Funding: Universitas Ahmad Dahlan (UAD) and BKKBN DIY supported this study by funding research grants.

\section{References}

1. Jacobs B, Ir P, Bigdeli M, Annear PL, Van Damme W. Addressing access barriers to health services: An analytical framework for selecting appropriate interventions in low-income Asian countries. Health Policy and Planning. 2012;27(4):288-300.

2. Kim TJ, Vonneilich N, Lüdecke D, von dem Knesebeck O. Income, financial barriers to health care and public health expenditure: A multilevel analysis of 28 countries. Social Science and Medicine. 2017;176:158-65.

3. WHO. Health Systems: Improving Performance. The World Health Report 2000. Geneva: World Health Organization 2000; 2000.

4. WHO. The Republic of Indonesia Health System Review. In: Hort K, Patcharanararumol W, editors. Health Systems in Transition. Asia Pacific Observatory n Health Systems and Policies; 2017.

5. TNP2K. The Road to National Health Insurance (JKN). Jakarta, Indonesia: National Team for the Acceleration of Poverty Reduction; 2015.

6. Teplitskaya L, Ross R, Dutta A. Has Indonesia's National Health Insurance Scheme Improved
Family Planning Use? Washington DC; 2018.

7. Agustina R, Dartanto T, Sitompul R, Susiloretni KA, Suparmi, Achadi EL, et al. Universal health coverage in Indonesia: concept, progress, and challenges. The Lancet. 2019 Jan;393(10166):75102.

8. BKKBN. Pedoman Penyelenggaraan Pelayanan Keluarga Berencana dalam Jaminan Kesehatan Nasional. Jalal F, Witjaksono J, Rahayu A, editors. Jakarta: Penerbit DITJALPEM BKKBN; 2014.

9. Misnaniarti, Ayuningtyas D. Unmet need for family planning in Indonesia and the policy strategy of intervention in several countries. International Journal of Reproduction, Contraception, Obstetrics and Gynecology. 2016;5(6):1680-5.

10. Tarigan I, Suryati T. Gambaran Out of Pocket pada Awal Era JKN di Indonesia. Jurnal Penelitian dan Pengembangan Pelayanan Kesehatan. 2017;1(2):141-6.

11. Nugraheni WP, Hartono RK. Determinan Pengeluaran Kesehatan Katastropik Rumah Tangga Indonesia Pada Tahun Pertama Implementasi Program JKN. Buletin Penelitian Kesehatan. 2016;45(1):27-36.

12. BPS, BKKBN, Kementerian Kesehatan, USAID. Survei Demografi dan Kesehatan Indonesia 2017. Jakarta; 2018.

13. Kutzin J. Health financing for universal coverage and health system performance: concepts and implications for policy. Bulletin of the World Health Organization. 2013;91(8):602-11.

14. WHO. The World Health Report: Health Systems Financing: The Path to Universal Coverage. Geneva: World Health Organization; 2010.

15. Cashin C, Hendrartini Y, Trisnantoro L, Pervin A, Taylor C, Hatt L. HFG Indonesia Strategic Health Purchasing (November 2016-August 2017): Final Report. Bethesda; 2017.

16. Ghoddoosi-Nezhad D, Janati A, Arab Zozani M, Doshmagir L, Sadeghi Bazargani H, Imani A. Is strategic purchasing the right strategy to improve a health system's performance? A systematic review. Bali Medical Journal. 2017;6(1):102.

17. Pinandari AW, Wilopo SA. Position and Chance of Indonesia Family Planing to Achieve RPJMN 
2015-2019 and FP2020 Targets. Jurnal Kesehatan Masyarakat. 2018;14(1):90-8.

18. Radovich E, Dennis ML, Barasa E, Cavallaro FL, Wong KLM, Borghi J, et al. Who pays and how much? A cross-sectional study of out-of-pocket payment for modern contraception in Kenya. BMJ Open. 2019;9(2):1-11.

19. Eldridge C, Staples MH. A Synthesis Of Recent Learnings On The Integration Of Family Planning In Universal Health Coverage Schemes. Impact for Health. 2018;(December).

20. Appleford G, Ramarao S. Health Financing and Family Planning in the Context of Universal Health Care : Connecting the Discourse in Kenya. Population Council Knowledge Commons; Social and Behavioral Science Research (SBSR). New York; 2019.

21. Mahumud RA, Sarker AR, Sultana M, Islam Z, Khan J, Morton A. Distribution and determinants of out-of-pocket healthcare expenditures in Bangladesh. Journal of Preventive Medicine and
Public Health. 2017;50(2):91-9.

22. Mohanty SK, Mishra S, Chatterjee S, Saggurti N. Pattern and correlates of out-of-pocket payment (OOP) on female sterilization in India, 1990-2014. BMC Women's Health. 2020;20(1):28-31.

23. Finer LB, Sonfield A, Jones RK. Changes in out-of-pocket payments for contraception by privately insured women during implementation of the federal contraceptive coverage requirement. Contraception. 2014;89(2):97-102.

24. Tibaijuka L, Odongo R, Welikhe E, Mukisa W, Kugonza L, Busingye I, et al. Factors influencing use of long-acting versus short-acting contraceptive methods among reproductive-age women in a resource-limited setting. BMC Women's Health. 2017;17(1):1-13.

25. Ensor T, Quayyum Z, Nadjib M, Sucahya P. Level and determinants of incentives for village midwives in Indonesia. Health Policy and Planning. 2009;24(1):26-35. 